\title{
INTEGRATED NEUROMUSCULAR INHIBITION TECHNIQUE LEBIH MENURUNKAN NILAI DISABILITAS LEHER DARIPADA AKTIVASI DEEP CERVICAL FLEXOR MUSCLE PADA MYOFASCIAL PAIN SYNDROME OTOT UPPER TRAPEZIUS
}

\author{
Nitaya Putri Nur Hidayati ${ }^{1}$, Dewa Putu Gede Purwa Samatra ${ }^{2}$, S. Indra Lesmana ${ }^{3}$, \\ Nyoman Mangku Karmaya ${ }^{4}$, Ni Wayan Tianing ${ }^{5}$, I Putu Gede Adiatmika ${ }^{6}$ \\ ${ }^{1}$ Program Studi Magister Fisiologi Keolahragaan Universitas Udayana, Denpasar \\ ${ }^{2}$ Divisi Neurologi, Fakultas Kedokteran, Universitas Udayana/RSUP Sanglah, Denpasar \\ ${ }^{3}$ Fakultas Fisioterapi, Universitas Esa Unggul, Jakarta \\ ${ }^{4,5,6}$ Fakultas Kedokteran, Universitas Udayana, Denpasar \\ E-mail: nitayaputrin@gmail.com
}

\begin{abstract}
ABSTRAK
Pendahuluan: Perkembangan teknologi memudahkan seseorang untuk menyelesaikan tugas sehari-hari. Banyak orang menghabiskan sebagian besar waktunya untuk berada di depan gawai. Dampak negatif yang timbul pada penggunaan gawai yang berlebihan adalah buruknya postur tubuh, karena seseorang cenderung akan duduk dengan posisi leher yang membungkuk ke depan. Hal tersebut akan menyebabkan ketidakseimbangan kerja otot area leher, terjadi ketegangan terus menerus tanpa disertai relaksasi yang cukup pada otot upper trapezius akan menimbulkan myofascial pain syndrome pada otot tersebut. Tujuan Penelitian: Untuk menemukan intervensi fisioterapi yang efektif dan efisien guna menurunkan nilai disabilitas leher pada myofascial pain syndrome otot upper trapezius. Metode: Penelitian ini bersifat experimental, dengan pretest-posttest design dengan randomisasi sebagai desain penelitiannya. Intervensi dilakukan 3 kali seminggu selama 4 minggu. Sampel merupakan pasien di klinik Fitasoma, Colomadu, Karanganyar, yang terdiri dari 19 orang berusia 25 - 40 tahun, dibagi menjadi 2 kelompok yang terdiri dari Kelompok I dengan perlakuan intervensi integrated neuromuscular inhibition technique yang berjumlah 9 orang dan Kelompok II dengan perlakuan aktivasi deep cervical flexor muscle yang berjumlah 10 orang. Pengukuran nilai disabilitas menggunakan Neck Disability Index. Hasil: Terdapat penurunan nilai disabilitas leher yang bermakna pada ke dua kelompok. Pada Kelompok I didapat rerata dari 40,00 menjadi 21,67 dan pada Kelompok II di dapat rerata dari 39,10 menjadi 30,30. Uji beda setelah perlakuan pada masing-masing kelompok didapatkan nilai $\mathrm{p}=0,042$ dan selisih rerata 18,33 pada Kelompok I dan 8,80 pada Kelompok II yang berarti Integrated Neuromuscular Inhibition Technique lebih baik daripada aktivasi deep cervical flexor muscle dalam menurunkan nilai disabilitas leher.
\end{abstract}

Kata kunci: Integrated Neuromuscular Inhibition Technique, deep cervical flexor, myofascial pain syndrome 


\title{
INTEGRATED NEUROMUSCULAR INHIBITION TECHNIQUE MORE REDUCE NECK DISABILITY SCORE THAN DEEP CERVICAL FLEXOR MUSCLE ACTIVATION IN MYOFASCIAL PAIN SYNDROME OF UPPER TRAPEZIUS MUSCLE
}

\begin{abstract}
Background: The development of technology makes it easy for someone to complete everyday tasks. Many people spend most of their time in front of the device. The negative impact arising from the excessive use of devices is poor posture, because a person will tend to sit with his neck bent forward. This will cause an imbalance in the neck area of the muscles work, there is continuous tension without adequate relaxation in the upper trapezius muscle will cause myofascial pain syndrome in the muscle. Purpose: To analyze an effective and efficient of physiotherapy intervention for increase disability index score in myofascial pain syndrome of upper trapezius muscle. Method: This research employed experimental with two group pre and post test design with randomization. Treatment are conducted 3 times a week for 4 weeks. This research intend to take research subject from patient in Fitasoma physiotherapy clinic in Colomadu, Karanganyar, consisting of 19 responden aged between 25 - 40 years, divided into two groups consisting of group I treatment at integrated neuromuscular inhibiton technique was 9 people and group II deep cervical flexion activation ammount 10 people. Measurment of disability score by using Neck Disability Index. Result: The analysis showed decrease in the score of neck disability significantly in both groups. In group I, the mean was obtained from 40.00 to 21.67 and in second group it was obtained from 39.10 to 30.30 . In the post test testing in both groups get p value 0.042 and mean difference in a group I is 18.33 and group II is 8.80 it means integrated neuromuscular inhibition technique is better than deep cervical flexor muscle activation to decrease neck disability.
\end{abstract}

Keywords: Integrated Neuromuscular Inhibition Technique, deep cervical flexor, myofascial pain syndrome

\section{PENDAHULUAN}

Bersamaan dengan pesatnya perkembangan teknologi dan budaya yang tidak dapat dihindarkan lagi, masalah kesehatan menjadi faktor yang sangat penting bagi kelangsungan hidup manusia. Kemajuan teknologi yang semakin memudahkan segala aktivitas manusia akan berakibat pada berubahnya pola hidup manusia yang menuju ke arah negatif. Salah satunya kecenderungan pola hidup yang serba duduk (sedentary living), seseorang yang cenderung kurang gerak atau banyak duduk akan meningkatkan potensi terjadinya berbagai jenis penyakit tidak menular dan penyakit degeneratif.
Seiring dengan kemajuan penggunaan gawai untuk menyelesaikan tugas sehari-hari, memberikan kontribusi terhadap peningkatan gangguan muskuloskeletal ${ }^{1}$. Dampak negatif yang timbul pada penggunaan gawai adalah buruknya postur tubuh, karena seseorang cenderung duduk dengan posisi leher yang menekuk ke depan. Hal tersebut dapat menyebabkan perubahan kurva cervical dan uper thoracal, akibatnya akan terjadi ketegangan otot di area leher dan bahu sehingga akan menekan pembuluh darah yang mengakibatkan nyeri kepala ${ }^{2}$.

Sikap tubuh yang kurang baik yaitu posisi bahu membungkuk dan leher cenderung maju ke depan saat menggunakan gawai, membaca buku, ataupun bekerja di depan komputer, dapat 
menyebabkan neck dysfunction. Neck disfunction merupakan faktor penyebab munculnya disabilitas leher yang diakibatkan dari suatu patologi yang disebut forward head posture. Forward head posture merupakan suatu kondisi dimana posisi kepala berada lebih ke anterior dari bahu, yang dalam keadaan normal posisi tengah bahu sejajar dengan meatus auditory external. Posisi ini memberikan stimulus long-term low-intensity pada otot upper trapezius. Kondisi tersebut dapat membentuk formasi siklus spasme-nyerispasme, sehingga berakibat pada penurunan pasokan darah dan oksigen serta nutrisi ke dalam otot, kemudian penurunan kemampuan otot untuk terulur maksimal karena adanya hambatan di beberapa serabut otot sehingga membentuk bundel taut band yang pada akhirnya terjadi myofascial trigger points pada otot tersebut ${ }^{3}$.

Myofascial pain syndrome adalah suatu kondisi yang disebabkan adanya ketegangan pada otot sehingga mengalami pemendekan dan kurangnya fleksibilitas, sehingga terjadi perlengketan dari pembungkus otot (fascia) yang berkaitan dengan timbulnya nyeri yang kronis ${ }^{4}$. Gejala utama pada myofascial pain syndrome di antaranya timbulnya rasa nyeri lokal maupun nyeri menjalar, teraba ketegangan dan taut band pada otot. Trigger points sebagai patofisiologi dan manifestasi klinis yang utama dari myofascial pain syndrome. Adanya taut band dan ketegangan otot akan menyebabkan impairment pada fungsi dan struktur tubuh, keterbatasan aktivitas, sehingga menyebabkan penurunan kemampuan fungsional leher yang menuju ke disabilitas leher 5 .

Otot upper trapezius adalah yang paling sering mengalami ketegangan hingga didapati myofascial trigger points, karena otot upper trapezius adalah otot yang paling banyak menanggung berat kepala saat posisi forward head posture ${ }^{6}$.

Beberapa teknik terapi seperti deep pressure massage, stretch therapy with spray, ultrasound, Transcutaneus Electric Nerve Stimulation (TENS) dan superficial heat mampu menginaktivasi myofascial pain syndrome ${ }^{7}$.
Latihan penguatan otot deep cervical flexor muscle berhasil memperbaiki postur leher dan bahu untuk meningkatkan keseimbangan kerja otot di area leher sehingga mampu menurunkan gejala pada nyeri leher dan penurunan disabilitas leher yang di pantau secara jangka panjang ${ }^{8}$.

\section{METODE PENELITIAN}

Penelitian ini bersifat experimental, dengan rancangan penelitian pretest-posttest group design. Kelompok I diberikan perlakuan integrated neuromuscular inhibition technique, sedangan Kelompok II diberikan aktivasi deep cervical flexor muscle. Pengukuran disabilitas leher menggunakan Neck Disability Index(NDI).

Masing-masing perlakuan dilakukan 3 kali seminggu selama 4 minggu. Sampel merupakan pasien di klinik Fisioterapi Fitasoma, Colomadu, Karanganyar, yang terdiri dari 19 orang berusia 25 - 40 tahun, dibagi menjadi 2 kelompok yang terdiri dari Kelompok I berjumlah 9 orang dan Kelompok II berjumlah 10 orang.

\section{HASIL PENELITIAN}

\section{Karakteristik Subjek Penelitian}

Tabel 1

Karakteristik subjek penelitian

\begin{tabular}{|c|c|c|}
\hline Variabel & $\mathrm{f}$ & Rerata \pm SD \\
\hline \multicolumn{3}{|l|}{ Jenis Kelamin } \\
\hline \multicolumn{3}{|l|}{ Laki-laki } \\
\hline Kelompok INIT & 3 & - \\
\hline Kelompok $D C F$ & 4 & - \\
\hline \multicolumn{3}{|l|}{ Perempuan } \\
\hline Kelompok INIT & 9 & - \\
\hline Kelompok $D C F$ & 6 & - \\
\hline \multicolumn{3}{|l|}{ Usia (tahun) } \\
\hline Kelompok INIT & - & $29,00 \pm 4,387$ \\
\hline Kelompok $D C F$ & - & $32,10 \pm 5,216$ \\
\hline \multicolumn{3}{|l|}{$\begin{array}{c}\text { Waktu posisi statis/hari } \\
\text { (jam) }\end{array}$} \\
\hline $\begin{array}{l}\text { (jam) } \\
\text { Kelomnok INIT }\end{array}$ & - & $5,44 \pm 0,882$ \\
\hline $\begin{array}{l}\text { Kelompok INIT } \\
\text { Kelompok } D C F\end{array}$ & - & $5,50 \pm 0,972$ \\
\hline
\end{tabular}

Pada Tabel 1 berisi distribusi karakteristik subjek yang menunjukkan total subyek 
penelitian adalah 19 orang $(\mathrm{n}=19)$, dengan distribusi pada Kelompok INIT sejumlah 9 dan Kelompok $D C F$ berjumlah 10 orang. Kelompok INIT dan DCF di dominasi oleh jenis kelamin perempuan. Distribusi usia pada Kelompok INIT di dapatkan reratanya 29 tahun, sedangkan pada Kelompok DCF 32 tahun. Sementara berdasarkan lama waktu subjek berada dalam suatu posisi yang statis pada kepala dan bahu di masing-masing kelompok adalah 5,4 jam per hari pada Kelompok INIT dan 5,5 jam per hari pada Kelompok $D C F$.

\section{Uji Normalitas dan Homogenitas}

Tabel 2

Uji Normalitas dan Homogenitas

\begin{tabular}{|c|c|c|c|c|c|}
\hline \multirow{3}{*}{ NDI } & \multicolumn{4}{|c|}{ Shapiro Wilk Test } & \multirow{3}{*}{$\begin{array}{c}\text { Laven } \\
\text { e's } \\
\text { Test } \\
\text { (nilai } \\
\text { p) }\end{array}$} \\
\hline & \multicolumn{2}{|c|}{ Kelompok INIT } & \multicolumn{2}{|c|}{ Kelompok $D C F$} & \\
\hline & $\begin{array}{c}\text { Rerata } \pm \\
\text { SD }\end{array}$ & $\mathrm{p}$ & $\begin{array}{l}\text { Rerata } \pm \\
\text { SD }\end{array}$ & $\mathrm{p}$ & \\
\hline $\begin{array}{l}\text { Pre } \\
\text { Test }\end{array}$ & $\begin{array}{c}40,00 \pm \\
11,391\end{array}$ & 0,300 & $\begin{array}{c}39,10 \pm \\
10,429\end{array}$ & 0,076 & 0,641 \\
\hline $\begin{array}{l}\text { Post } \\
\text { Test }\end{array}$ & $\begin{array}{c}21,67 \pm \\
4,153\end{array}$ & 0,646 & $\begin{array}{c}30,30 \pm \\
11,096\end{array}$ & 0,050 & \\
\hline
\end{tabular}

Hasil uji normalitas menggunakan ShapiroWilk test didapatkan nilai $\mathrm{p}>0,05$ pada ke dua kelompok. Hal tersebut menunjukkan bahwa nilai disabilitas leher yang diukur menggunakan form Neck Disability Index pada ke dua kelompok berdistribusi normal. Hasil uji homogenitas dengan levene test di peroleh hasil nilai $\mathrm{p}$ sebesar 0,641 yang berarti tidak terdapat perbedaan rerata atau data homogen pada ke dua kelompok sebelum perlakuan.

\section{Uji Beda Nilai Disabilitas Leher Sebelum dan Setelah Perlakuan pada masing- masing kelompok}

Tabel 3

Hasil Uji Beda Sebelum dan Setelah Perlakuan

\begin{tabular}{lccc}
\hline & $\begin{array}{c}\text { Sebelum } \\
\text { perlakuan }\end{array}$ & $\begin{array}{c}\text { Setelah } \\
\text { perlakuan }\end{array}$ & \\
& & $\mathrm{p}$ \\
& $\begin{array}{c}\text { Rerata } \pm \\
\text { SD }\end{array}$ & $\begin{array}{c}\text { Rerata } \pm \\
\text { SD }\end{array}$ & \\
& & & \\
& $40,00 \pm$ & $21,67 \pm$ & 0,001 \\
Kelompok INIT & 11,391 & 4,153 & \\
& & & \\
& $39,10 \pm$ & $30,30 \pm$ & 0,000 \\
Kelompok $D C F$ & 10,429 & 11,096 & \\
& & &
\end{tabular}

Berdasarkan Tabel 3 didapatkan hasil uji beda rerata nilai disabilitas leher sebelum dan setelah perlakuan menggunakan Paired Sample T-Test pada kelompok Integrated Neuromuscular Inhibition Technique didapatkan nilai $\mathrm{p}=0,001(\mathrm{p}<0,05)$ yang berarti bahwa Integrated Neuromuscular Inhibition Technique dapat menurunkan disabilitas leher pada myofascial pain syndrome otot upper trapezius.

Sedangkan pada kelompok aktivasi Deep Cervical Flexor muscle didapatkan nilai $\mathrm{p}=$ $0,000(\mathrm{p}<0,05)$ yang berarti bahwa aktivasi Deep Cervical Flexor dapat menurunkan disabilitas leher pada myofascial pain syndrome otot upper trapezius.

\section{Uji Beda Rerata Nilai Disabilitas Leher Setelah Perlakuan.}

Tabel 4

Hasil uji beda kedua kelompok

\begin{tabular}{|c|c|c|c|}
\hline & \multicolumn{3}{|c|}{$\begin{array}{c}\text { Nilai Disabilitas Leher Setelah } \\
\text { Perlakuan }\end{array}$} \\
\hline & $\begin{array}{l}\text { Rerata } \pm \\
\quad \text { SD }\end{array}$ & $\begin{array}{l}\text { Selisih Rerata } \\
\quad \pm \text { SD }\end{array}$ & $\mathrm{p}$ \\
\hline $\begin{array}{l}\text { Kelompok } \\
\text { INIT }\end{array}$ & $\begin{array}{c}21,67 \pm \\
4,153\end{array}$ & $18,33 \pm 10,559$ & \multirow{2}{*}{0,042} \\
\hline $\begin{array}{l}\text { Kelompok } \\
D C F\end{array}$ & $\begin{array}{c}30,30 \pm \\
11,096\end{array}$ & $8,80 \pm 2,201$ & \\
\hline
\end{tabular}

Berdasarkan Tabel 4 uji beda setelah perlakuan pada kelompok Integrated Neuromuscular Inhibition Technique dan kelompok aktivasi Deep Cervical Flexor muscle di dapatkan hasil nilai $\mathrm{p}=0,042(\mathrm{p}<0,05)$ yang berarti terdapat perbedaan yang bermakna 
antara ke dua kelompok tersebut setelah diberi perlakuan oleh karena ditemukannya nilai yang signifikan.

Pada uji beda rerata post kedua kelompok ditemukan perbedaan penurunan disabilitas leher yang lebih baik pada pasien myofascial pain syndrome otot upper trapezius setelah mendapatkan intervensi integrated neuromuscular inhibition technique dibandingkan dengan pemberian aktivasi deep cervical flexor.

\section{PEMBAHASAN}

\section{Integrated \\ Neuromuscular Inhibition Technique dapat Menurunkan Nilai Disabilitas Leher pada Myofascial Pain Syndrome Otot Upper Trapezius}

Integrated Neuromuscular Inhibition Technique merupakan kombinasi dari 3 teknik yaitu ischemic compression, strain counterstrain, dan muscle energy technique. Saat dilakukan ischemic compression pada titik peka nyeri atau trigger point, mampu menyebabkan lokal iskemik sehingga akan memblokir aliran darah, kemudian diikuti dengan pelepasan tekanan yang akan menyebabkan reperfusi jaringan sehingga terjadi peningkatan aliran darah di area tersebut, dan otot menjadi lebih rileks serta fleksibilitas meningkat. Penekanan pada teknik ischemic compression juga akan menyebabkan peluruhan pada tautband karena friksi pada serabut otot yang mengalami crosslink, sehingga terjadi pelepasan perlengketan jaringan ${ }^{8}$.

Teknik strain counterstrain yang merupakan teknik manipulasi yang menerapkan teknik penekanan yang disertai dengan pemberian posisi nyaman pada jaringan yang patologis. Hal tersebut dapat menstimulasi muscle spindle yang mengalami spasme sehingga menghasilkan aktivasi dari propioseptor yang mempersarafi muscle spindle. Rangsangan yang diterima oleh muscle spindle juga akan menyebabkan terjadinya relaksasi secara reflek pada otot yang spasme. Penekanan yang diberikan dapat menghasilkan aliran sirkulasi yang meningkat setelah penekanan dilepas karena mampu menghambat nosisensorik sehingga sirkulasi lancar dan perbaikan nutrisi terhadap otot yang tegang dan nyeri dapat berkurang ${ }^{9}$.

Teknik yang ketiga pada INIT yaitu muscle energy technique (MET). Pada MET melibatkan kontraksi otot dalam arah yang sangat terkontrol dengan intensitas kekuatan yang bervariasi dan dengan berbagai variasi tingkat tahanan yang diaplikasikan oleh terapis. Dasar fisiologis teknik yang digunakan adalah autogenic (postisometric) inhibition yaitu setelah otot berkontraksi isometrik, secara otomatis akan diikuti dengan relaksasi otot. Mekanisme yang terjadi adalah aferen dari ke dua reseptor di golgi tendon dan aferen gamma dari reseptor muscle spindle memberikan feedback ke medulla spinalis. Saat dilakukan kontraksi otot secara isometrik, maka akan menstimulasi reseptor golgi tendon organ. Impuls saraf aferen dari golgi tendon organ masuk ke medula spinalis melalui dorsal horn dan bertemu dengan motor neuron inhibitory, sehingga mampu menghentikan pelepasan impuls motor neuron eferen dan karena itu mencegah kontraksi lebih lanjut, tonus otot berkurang, yang selanjutnya akan menghasilkan relaksasi dan perpanjangan serabut otot ${ }^{10}$.

\section{Aktivasi Deep Cervical Flexor Muscle dapat Menurunkan Nilai Disabilitas Leher pada Myofascial Pain Syndrome}

Seseorangan dengan myofascial trigger points syndrome otot upper trapezius terjadi perubahan postur leher dan kepala menjadi forward head posture akibat dari penurunan aktivasi pada deep cervical flexor muscle (longus capitis dan longus colli) dan ketegangan pada otot upper trapezius. Forward head posture dapat terjadi pada seseorang dengan aktivitas sehari-hari yang berada di depan komputer lebih dari 4 jam per hari ${ }^{11}$. Program terapi latihan yang difokuskan pada aktivasi deep cervical flexor muscle akan memperbaiki kurva lordotik cervical sehingga aktivasi otot deep cervical flexor dan upper trapezius 
berjalan dengan sinergi, ketika otot deep cervical flexor aktif maka otomatis terjadi penurunan ketegangan otot upper trapezius. Sehingga otot upper trapezius menjadi rileks, aliran darah lebih lancar, fleksibilitas otot meningkat yang akan mengakibatkan penurunan nyeri dan disabilitas leher ${ }^{12}$.

Rekruitmen dan daya tahan otot deep cervical flexor merupakan faktor yang penting pada pasien dengan nyeri leher di sertai myofascial syndrome dan nyeri kepala cervicogenic $^{13}$. Hal tersebut berhubungan dengan gejala pada kondisi upper crossed syndrome. Pada upper crossed syndrome terjadi abnormalitas postur yang berakibat kelemahan dan lengthening dari otot upper back dan otototot leher serta terjadi ketegangan dan shortening dari kebalikannya yaitu pada ototbagian depan dada dan leher, disebut juga prinsip reciprocal inhibition. Reciprocal inhibition adalah reaksi otomatis berupa inhibisi pada alfa motor neuron otot antagonis akibat dari kontraksi otot agonis.

\section{Integrated Neuromuscular Inhibition Technique lebih menurunkan nilai disabilitas leher dari pada aktivasi deep cervical flexor muscle pada myofascial pain syndrome otot upper trapezius}

Myofascial pain syndrome otot upper trapezius menyebabkan terjadi keluhan muskuloskeletal yang diakibatkan posisi statis dengan postur leher yang salah saat beraktivitas dalam waktu yang lama sehingga menyebabkan muscle imbalance, yaitu ketegangan atau spasme pada otot upper trapezius dan kelemahan pada otot antagonisnya yaitu otot longus capitis dan longus colli. Spasme otot yang berkepanjangan dapat menyebabkan vasokontriksi pembuluh darah yang menimbulkan rasa tidak nyaman atau nyeri sehingga terjadi penurunan produktivitas ${ }^{14}$.

Pemberian Integrated Neuromuscular Inhibition Technique, memberikan efek pada penurunan nyeri dengan melepaskan perlengketan jaringan serta mengakibatkan rileksasi jaringan otot dan fascia sehingga mampu menurunkan spasme serta memperbaiki sirkulasi pembuluh darah dan metabolisme jaringan.

Aktivasi deep cervical flexor mampu memperbaiki forward head posture melalaui latihan penguatan otot anterior leher. Jika otot area anterior leher menjadi kuat, maka otot di area upper back dan shoulder yaitu otot upper trapezius dengan otomatia akan release. Sehingga Center Of Gravity (COG) dari kepala mampu kembali ke posterior (normal) yang akan menurunkan beban dari leher, dan juga menurunkan penekanan yang tidak merata di area otot, ligamen, saraf sehingga postur leher menjadi lebih baik dan keseimbangan kontraksi otot - otot area leher akan lebih terjaga yang diikuti dengan releasenya otot upper trapezius.

Latihan aktivasi deep cervical flexor muscle berhasil dalam menurunkan keluhan yang signifikan pada myofascial trigger point syndrome setelah dipantau dalam 3 bulan. Karena suatu latihan akan merubah kondisi sarkomer otot dalam waktu lebih dari 6 minggu, namun dapat memberikan efek secara jangka panjang ${ }^{15}$. Latihan deep cervical flexor mampu memberikan efek yang signifikan dalam menurunkan nyeri dan meningkatkan kemampuan fungsional pada penderita chronic neck pain setelah 8 minggu perlakuan. Sedangkan pada INIT mampu menurunkan nyeri, melepaskan perlengketan jaringan dan meningkatkan fleksibilitas otot dalam jangka waktu yang relatif singkat, bahkan dalam satu kali perlakuan pun pasien mampu merasakan penurunan nyeri ${ }^{16}$.

Beberapa hasil penelitian yang membuktikan bahwa Integrated Neuromuscular Inhibition Technique lebih baik daripada aktivasi deep cervical flexor muscle karena ada beberapa mekanisme atau aktivitas yang secara signifikan dapat menurunkan milai disabilitas leher dalam waktu yang cukup singkat seperti adanya penekanan lokal pada trigger point saat otot posisi rileks akan mengurangi ketegangan karena aliran darah yang lebih lancar setelah dilepaskannya penekanan.

Selain itu, pada strain counterstrain juga mampu menginaktivasi saraf penghantar rasa 
nyeri, menghasilkan pemanjangan pada sarkomer. Sedangkan Muscle Energy Technique akan menstimulasi golgi tendon organ yang berperan dalam rileksasi otot dengan cara kontraksi isometrik, yang juga akan meningkatkan proses metabolisme dan sirkulasi lokal. Jika sirkulasi lokal lancar, maka tidak terjadi penumpukan asam laktat dan zat sisa metabolisme yang lain seperti substansi $\mathrm{P}$ yang di produksi melalui proses inflamasi sehingga nyeri dapat berkurang ${ }^{17}$.

Penelitian ini merupakan penelitian untuk mengevaluasi penurunan nilai disabilitas leher dalam jangka pendek. Pada Integrated Neuromuscular Inhibition Technique mampu memberikan pengaruh yang signifikan pada penurunan nilai disabilitas leher dalam waktu yang cepat karena efek fisiologis yang dihasilkan dari ketiga metode INIT memberikan feed back secara langsung. Sedangkan aktivasi deep cervical flexor muscle adalah suatu bentuk latihan penguatan pada otot, dimana menurut Mackanzie (2000) perubahan fisiologi pada sarkomer di dalam otot terjadi secara berkelanjutan jika melakukan latihan yang teratur dan terprogram setelah 8 - 12 minggu.

Latihan dengan frekuensi 3 kali setiap minggunya akan tampak pengaruhnya pada otot setelah 8 minggu. Hal ini dikarenakan terjadinya peningkatan kemampuan kerja otot yang disebabkan oleh perubahan fisiologis pada sistem neuromuskular. Perubahan tersebut di antaranya penambahan ukuran serabut otot (hipertrofi) sehingga akan menyebabkan kontraksi otot yang lebih kuat dan meningkatkan ketahanan otot ${ }^{18}$.

\section{KETERBATASAN PENELITIAN}

Penelitian ini baru menyimpulkan penurunan nilai disabilitas leher untuk jangka pendek saja. Diharapkan pada penelitian selanjutnya untuk menambah waktu pengukuran yang lebih panjang untuk mengetahui efisiensi dan efektifitas perlakuan dalam jangka panjang.

\section{SIMPULAN}

1. Integrated Neuromuscular Inhibition Technique dapat menurunkan nilai disabilitas leher pada myofascial pain syndrome otot upper trapezius.

2. Aktivasi deep cervical flexor muscle dapat menurunkan nilai disabilitas leher pada myofascial pain syndrome otot upper trapezius.

3. Integrated Neuromuscular Inhibition Technique lebih menurunkan nilai disabilitas leher daripada aktivasi deep cervical flexor muscle pada myofascial pain syndrome otot upper trapezius.

\section{DAFTAR PUSTAKA}

1. Hakala, P. T., Saarni L., Punamaki RL., Wallenius MA., Nygard CH., Rimpela AH. 2012. Musculoskeletal symptomps and computer use among finnish adolescentspain intensity and inconvenience to everyday life: a cross-sectional study. $B M C$ musculoskeletal disorders. 13: 41

2. Mehdikani, R., Okhtovatian, F. Immediate effect of muscle energy technique on latent trigger point of upper trapezius muscle. Clinical chiropractic, 2012. 112-120

3. Clark, B. C., Thomas, J. S., Walkowski, S. A., Howell, J. N. 2012. The biology of manual therapies. Journal of the American Osteophatic Association. 112(9). 617-629

4. Lofriman. 2008. Nyeri pada Otot(Myofascial Pain). Vol.1

5. Salavati et al., 2017. Reliability of the Upper Trapezius Muscle and Fascia Thickness and Strain Ratio Measures by Ultrasonography and Sonoelastography in Participants With Myofascial Pain Syndrome. Journal of Chiropractic Medicine. 1-8.

6. Ravichandran, Ponni, Aseer. 2016. Effectiveness of ischemic compression on trapezius myofascial trigger points in neck 
pain. International Journal of Physiotherapy. 3(2). 186-192.

7. Desai, M., Saini, V., Saini, S. 2013. M. Myofascial Pain Syndrome: A Treatment Review. Journal of Pain Therapy. Vol 2:21-36.

8. Aguilera JF, Martin D, Masnet R, Botella A, Soler L, Morell. (2010). Immediate effects of Ultrasound and Ischemic Compression Techniques for the Treatment of Trapezius Latent Myofascial Trigger Points in Health Subjects:A Randomized Controlled Study. Journal of Manipulative. 32(7):515-20.

9. Wibowo, A.T. 2013. Kombinasi Strain Conterstrain pada Intervensi Ultrasound dalam Mengurangi Nyeri Myofascial Syndrome Musculus Rhomboideus. (Skripsi). Universitas Esa Unggul.

10. Chaitow L. 2006. Muscle Energy Technique. 3rd edition. London, UK: Churchill Livingstone.

11. Dewi, Puspa, L K. Andayani, Nopi, L ,N. Dinata, Krisna, M. 2015. Intervensi Integrated Neuromuscular Inhibitation Technique (INIT) Dan Infrared Lebih Baik Dalam Menurunkan Nyeri Myofascial Pain Syndrome Otot upper Trapezius Dibandingkan intervensi Myofascial Release Technique (MRT) Dan Infrared Pada Mahasiswa Fisioterapi Fakultas Kedokteran Universitas Udayana. Skripsi. Universitas Udayana.

12. Ylinen J, Hakkinen A, Nykanen $M$, Kautiainen H, Takala EP. 2007. Neck Muscle Training in the Treatment of Chronic Neck Pain: a three year follow up study. Europa journals and books on medicine. 2007 June;43(2):161-9.

13. Middleditch, A,. Oliver J,. 2005. Functional Anatomy of the Spine: Second Edition. Philadelphia: Elsevier.

14. Dommerholt J., Carel B., Jo F. 2006. Myofascial Trigger Points: An EvidenceInformed Review. The Journal of Manual
\& Manipulative Therapy. Vol. 14, no 4. 203-221.

15. Sterling $M$, Jull G, Vicenzino $B$. Development of motor system dysfunction following whisplash injury. Pain, 2003, 103: $65-73$

16. Kim J. K., Kwag K. 2016. Clinical effects of deep cervical flexor muscle activation in patients with chronic neck pain. The Journal of Physical Therapy Science. 269273

17. Kumar G,. Sneha P,. Sivajyothi N,. 2015. Effectiveness of Muscle Energy Technique, Ischemic comression and strain counterstrain on Upper trapezius trigger points: A comparative study. International Journal of Physical Education, Sport and Health. Vol 1 no 3. 22-26

18. Dreger, R. W. 2006. Strength Training Consideration for Youth. Edmonton. 